\title{
The Social, Civic, and Political Uses of Instagram in Four Countries
}

\author{
SHELLEY BOULIANNE \\ MacEwan University, Canada \\ CHRISTIAN P. HOFFMANN \\ University of Leipzig, Germany
}

Instagram has more than 1 billion monthly users. Yet, little is known about how citizens engage with this platform. We use survey data (representative on age and gender) to examine citizens' Instagram use in four countries: the United States, Canada, the United Kingdom, and France $(n=6,291)$. The survey was administered to an online panel matched to the age and gender profile of each country (September to November 2019). Across the four countries, about $40 \%$ of respondents used Instagram. This platform is especially popular among young adults who cultivate larger networks compared to older adults. Compared to older adults who use Instagram, younger users are more likely to follow a news organization. We employ these usage patterns to infer different motivations for use, drawing on the uses and gratification approach. We find that this approach is most useful for understanding cross-national and gender differences. In particular, Americans cultivate larger social networks on Instagram compared to citizens from other countries, implying greater social interaction motives. Males are more likely to follow news organizations compared to females, which implies they have more informational motives for Instagram use. Socioeconomic differences

Shelley Boulianne: sjboulianne@gmail.com

Date submitted: 2021-03-03

Copyright (C) 2022 (Boulianne, Hoffmann). Licensed under the Creative Commons AttributionNonCommercial-NoDerivatives 4.0 International Public License. Available at: http://journalqd.org 
in Instagram adoption and types of uses are much smaller than the differences marked by age, gender, and country. This paper establishes the importance of Instagram use among citizens in four Western countries. Furthermore, we offer insights into the segments of the population that are intense users of Instagram, as well as different motivations for use.

Keywords: Instagram, cross-national, social networks; news media

\section{Introduction}

In 2018, Instagram had more than 1 billion monthly active users (Clement, 2019). The platform is a photo-sharing application with the option for text/captions to accompany posted images. The service was launched in October 2010 and purchased by Facebook in 2012. In the United States, Instagram is the third-most popular social media platform after YouTube and Facebook (Newman et al., 2020; Perrin \& Andersen, 2019).

We employ four-country survey data to examine who uses Instagram and how they use it, employing uses and gratifications as a broad theoretical framing. We focus on social uses as well as information uses. In recent years, numerous studies have explored how citizens use social media for information, and how social relations may affect the quality of information they encounter on these platforms (Allen et al., 2020; Altay et al., 2020; Fletcher et al., 2021; Petersen et al., 2020). However, much of this research has focused on Twitter, with some studies analyzing Facebook or mobile instant messenger services, such as WhatsApp. Despite its rapid growth in popularity, Instagram remains underexplored, and little is known about the social and information uses of this widely used platform.

We offer three unique contributions. First, we offer a comparison across four Western democracies. Existing research addresses the United States (USA) and the United Kingdom (UK); we offer additional insights into Canada and France, introducing 
multi-lingual and French-speaking countries into the study of platform adoption. We show that the frequency of Instagram use is similar in Canada and the USA, but slightly less in the UK and France. Second, we find that users' social networks on Instagram are quite small and that this platform is rarely used to establish direct ties to news organizations. This finding has implications for information flows; weak ties to quality news sources may leave Instagram users vulnerable to misinformation.

Third, as observed in other studies of social media platform adoption, we find strong age and gender differences in use. Young adults are distinctive in that they are intense users and have expansive social networks on Instagram. The youngest age groups are far more likely to use this platform for information compared to seniors. Females are less likely to use this platform for information compared to males. These insights are important because most of the survey research on Instagram use has focused on college students at American universities (Alhabash \& Ma, 2017; Kircaburun et al., 2020; ShaneSimpson et al., 2018; Sheldon \& Bryant, 2016). This focal point has merits given the strong age divide in use, but the age variations are largely assumed rather than assessed. The age differences we observe are not unique to the United States; Instagram is a popular tool for young people in all four countries. However, focusing on youth alone would offer a distorted view of Instagram use, as would focusing on the United States alone as Americans cultivate larger networks than respondents in other countries.

\section{Theoretical Framing: Uses and Gratification}

The uses and gratification (U\&G) approach has been widely employed to study media use, including the use of different social media platforms (e.g., Alhabash \& Ma, 2017; Kircaburun et al., 2020; Mantymaki \& Islam, 2016; Quan-Haase \& Young, 2010). The premise of this approach is that users are goal oriented and have expected outcomes from their media use. This area of research asks respondents to identify their motivation for using a platform. Studies vary in their lists of motives but, in general, information and social interaction are included and have been shown to guide social media adoption (e.g., 
Hargittai \& Litt, 2012). The scholarship about uses and gratifications related to Instagram use does not agree about the most salient motivation. However, studies tend to find that social interaction is low on the ranking of motivations for Instagram use (Alhabash \& Ma, 2017; Kircaburun et al., 2020; Sheldon \& Bryant, 2016). Shane-Simpson et al. (2018) find that $44 \%$ of college students surveyed like using Instagram to connect with others, but this number is small compared to Facebook (70\%). Yet, the surveillance of others' activities for social comparisons is a popular reason for Instagram use and predicts the amount of time spent on this platform (Ouwerkerk \& Johnson, 2016; Sheldon $\&$ Bryant, 2016). The studies also converge on the finding that information is not a strong motivation for Instagram use (Alhabash \& Ma, 2017; Kircaburun et al., 2020; ShaneSimpson et al., 2018; Sheldon \& Bryant, 2016).

The U\&G approach has been criticized as it relies on people to self-report their motivations for media use and assumes users are self-aware of and recall their motivations (see Alhabash \& Ma, 2017). Also, this theory ignores the network effects of technology adoption; people may choose a platform based on a social network effect, i.e., one's peer group, family, or other group uses the platform, rather than individual motivation. Quan-Haase and Young (2010) find the top reasons for joining Facebook are because a friend suggested it and one's family and friends are on it.

Rather than replicate this work (see extensive literature review in Alhabash \& Ma, 2017), we focus on self-reports about activities conducted using Instagram, which we use to infer the motivations for use. Conceptually, this approach is informed by revealed preference theory, which has been applied in consumer behavior studies to infer preferences from observed behavioral choices (Chambers \& Echenique, 2016). Revealed preference theory, which is a popular framework in economics research, posits that consumers' ability to explicate their motives for behavioral choices (e.g., buying decisions) is limited due to a lack of awareness and influences such as motivated reasoning. Preferences should therefore be inferred from behaviors rather than stated motives (cf., Hands, 2013). For example, we infer that people who have larger social 
networks are motivated to use the platform for maintaining social relations (Mantymaki \& Islam, 2016; Ouwerkerk \& Johnson, 2016) and people who follow news organizations are likely motivated by information. We organize these activities into social uses (social networks) and information uses (news organization). We focus on five predictors of Instagram use: age, gender, education, income, and country.

Much of the existing research focuses on college students, making it difficult to determine age differences in the motivations for using Instagram. As mentioned, studies of college students suggest information and social interaction score low in terms of motivations. However, we do not know if these findings are specific to youth or reflect all users. Our study offers insight into age patterns using a wide range of age groups to assess the degree to which young adults are distinctive in Instagram use.

Early research found female college students were more likely to join Instagram (Alhabash \& Ma, 2017; Mantymaki \& Islam, 2016; Sheldon \& Bryant, 2016), which scholars explained in terms of females' greater interest in social interaction. To the extent that Instagram is used for maintaining social relations, we might expect that women are more likely to use this platform. Using a sample of Chilean youth, Correa and Valenzuela (2021) did not find gender differences in the use of Instagram but did in terms of following news organizations on social media.

Schools are often sites for the adoption and use of new technologies. Hargittai (2020) notes that prior literature uses undergraduate student populations to examine use and non-use of platforms. Schools also offer digital skills training (Hargittai and Litt, 2012) that can contribute to more long-term trajectories of technology use. Being a student may also incentivize informational uses of platforms to gather background information for completion of assignments. Furthermore, if one's classmates are on a platform, this would be a motivation to also use this platform for social interaction (Quan-Haase \& Young, 2010). For this reason, we expect that Instagram adoption might 
differ based on education. Using a sample of Chilean youth, Correa and Valenzuela (2021) find socioeconomic differences in the use of Instagram.

Theories about income differences align with educational differences, as both relate to a broader concept of "socioeconomic status". Income may reflect different occupations; different occupations offer more training on the use of various technologies and may allow more autonomy in the use of these technologies. For example, Hargittai (2020) found income and education differences in the use of LinkedIn, which is a networking site for professionals to connect with colleagues as well as monitor job opportunities in their field. While this research did not consider Instagram, we expect that Instagram adoption may correlate with income.

The Reuters Institute Digital News Report 2020 reports that 27\% of French, 30\% of British and American, and 35\% of Canadian respondents use Instagram (Newman et al., 2020). In terms of news use, there are cross-national variations. Approximately $3 \%$ of British Instagram users consumed news on this platform, compared to 9\% of French, $10 \%$ of Canadians, and $8 \%$ of Americans. Despite the relatively low use, the report indicates "across age groups, use of Instagram for news has doubled since 2018 and looks likely to overtake Twitter over the next year" (Newman et al., 2020, p. 10). From a U\&G approach, we might infer Instagram use in the UK is less about information than other motivations. However, for all countries, news consumption is low and is likely a weak motivation for the use of Instagram.

Most of the research on social media has focused on Facebook and Twitter (Blank \& Lutz, 2017). In 2015, Blank and Lutz (2017) searched the Web of Science for Instagram and only found 37 studies with Instagram in the title. Russmann and Sevensson (2016) searched in 2016 and similarly concluded that little research on Instagram had been conducted. We updated the analysis of scholarship by searching Web of Science for Instagram in December 2020, finding a total of 556 hits on "Instagram" in the title of academic social sciences studies in this database. Research has indeed exploded on this 
topic, but this research is rarely based on a representative sample of users. Blank and Lutz's (2017) study is one exception; they do not find differences in Instagram use based on demographic variables in their sample of British Internet users. In a survey of Belgian Internet users, Hellemans and colleagues (2020) found that younger users, students, and females more frequently use Instagram. However, neither study explores types of uses. To build on this research, our first set of research questions (RQ1) is:

RQ1a: How frequently do people use Instagram?

RQ1b: How does the frequency of Instagram use differ by user characteristics (age, gender, education, income, and country)?

Early research on social media adoption highlights the importance of personality (Correa et al., 2010; Jenkins-Guarnieri et al., 2012; Ryan \& Xenos, 2011). People who are more sociable or extraverted are more likely to adopt social media, presumably because these media offer opportunities for social interaction (Kircaburun et al., 2020). Once they have adopted a platform, we might expect users to build networks to expand their opportunities for socializing. As mentioned, one of the gratifications of media use relates to social interaction. As such, we expect people seeking social interaction would build bigger networks on social media (Mantymaki \& Islam, 2016; Ouwerkerk \& Johnson, 2016).

The social network features of Instagram are similar to most social media platforms, allowing users to establish connections with friends and family as well as public figures and organizations, such as political parties and politicians (Bossetta, 2018). Similar to Twitter, the default is for Instagram to offer open access for establishing connections. One can follow another user without the second user's consent, unless the privacy settings have been changed to only allow dyadic relations, which is akin to Facebook "friends" (Bossetta, 2018). Posts on Instagram are, by default, open, but users can adapt these features; open accounts expand opportunities for social interaction and 
social networking. To further explore the social uses of Instagram, our next set of research questions (RQ2) is:

RQ2a: How large are people's social networks on Instagram?

RQ2b: How does the size of social networks maintained on Instagram differ by user characteristics (age, gender, education, income, and country)?

Users can follow different types of accounts that share news and information. A Pew study finds that, in the USA, Instagram is currently not a primary source of news, even among Instagram users (Shearer \& Grieco, 2019). As mentioned, the Digital News Report 2020 also reports that news consumption on Instagram is low (Newman et al., 2020). Yet, news consumption on Instagram may impact political participation. Based on a survey of Dutch Internet users, Van Cauwenberge and Broersma (2017) find that Instagram news use is positively related to online interpersonal political conversation, which in turn positively relates to (online and offline) political participation. The study did not, however, analyze to what degree political conversations are actually conducted on Instagram. Our third set of research questions (RQ3) focuses on information uses of Instagram:

RQ3a: To what extent are people using Instagram for information?

RQ3b: How do informational uses of Instagram differ by user characteristics (age, gender, education, income, and country)?

\section{Methods}

\section{Sample}

This paper uses survey data gathered in four countries from September to November 2019. The survey was administered by Kantar. The sample is based on an online panel with quotas used to ensure the age, education, and sex representation of the population in each country (see Appendix A). Instead of a response rate, Kantar reports on the weighting efficiency to reflect the match between the sample characteristics and 
the census profile of the country. The weighting efficiency is $99.2 \%$ for the USA, $99.7 \%$ for the UK, 99.8\% for France, and 97.7\% for Canada; these values reflect a near perfect match between our sample and the targeted population in each country and, as such, we did not weight the data. Pooling across samples, $51 \%$ of the sample are females $(.4 \%$ non-binary, $49 \%$ males). We excluded non-binary respondents as there were too few to conduct a separate analysis for this group. In Appendix A, we also compared the education distribution (having post-secondary or not) for the sample and official statistics. The data and analysis files are available: https://doi.org/10.6084/m9.figshare.17131445.v1.

Respondents had to be at least 18 years old to participate. The pooled sample includes 1,700 people from the United States, 1,542 from the United Kingdom, 1,510 from France, and 1,539 from Canada. The list of countries offers geographic diversity (North America and Europe) and linguistic diversity (English, French). Table 1 provides the estimates for the pooled sample and each country for all key variables.

Education was measured as a series of dummy variables: high school or less, some college, bachelor's degree, and more than a bachelor's degree (similar to Hargittai, 2020). This approach would reveal whether Instagram adoption and use differs by education group: perhaps the "some college" (including students) use this platform differently from other groups. Household income was originally coded in intervals and in the relevant currency for the respective country. The different currencies make crossnational comparisons difficult. As such, these categories were adjusted to create quintiles placing approximately $20 \%$ of the sample in each category, then converted into a series of dummy variables for analysis. This approach deals with the abnormal distribution of income, but also would reveal possible non-linear effects of income. In other words, this approach would reveal whether Instagram adoption and use differs by income grouping: perhaps the lowest income group (including students) and the highest income group use this platform, albeit for different reasons. These differences can be revealed using the dummy variable approach. 


\section{Measures}

The survey asked about eight social media platforms, of which Instagram was one $(n=6,291)$. We asked about frequency of use of these platforms in the past 12 months, offering responses of never, rarely, sometimes (time to time), and often (RQ1). For those people who reported use of Instagram $(n=2,504)$, we asked a series of follow-up questions. We asked about the number of Instagram accounts that respondents followed as well as their number of followers (RQ2). Rather than ask users to recall the exact number, we offered the following categories: 0 to 15,16 to 100,101 to 200, 201 to 400 , and finally more than 400. The categories are based on a 2017 survey of Twitter use in these countries in which we offered an open-ended question; these categories represent the natural breaks in the frequency distribution. We also asked whether the user followed a news organization on Instagram (RQ3).

\section{Analysis}

The analysis is presented as follows. We offer figures to depict the bivariate relationship between variables. This presentation helps to connect our findings to other descriptive sources, such as Pew studies and the Digital News Report 2020 (Newman et al., 2020; Perrin \& Andersen, 2019; Shearer \& Grieco, 2019). We also present multivariate analysis in tables to help isolate the specific effects of age, gender, education, income, and country. For dichotomous dependent variables, we conducted logistic regression analysis. We also dichotomized all independent variables to help with the interpretation of the odds ratio. A handful of our dependent variables have ordinal

scales (frequency, network size), so we conducted ordinary least squares regression and reported on standardized coefficients. 
Table 1. Descriptive statistics by country.

\begin{tabular}{lccccc}
\hline & $\begin{array}{c}\text { All } \\
\text { countries }\end{array}$ & USA & UK & France & Canada \\
\hline Females & $51.24 \%$ & $51.80 \%$ & $49.22 \%$ & $50.53 \%$ & $53.34 \%$ \\
\hline 18-24 years & $10.41 \%$ & $11.29 \%$ & $11.22 \%$ & $10.33 \%$ & $8.71 \%$ \\
25-34 years & $16.85 \%$ & $18.00 \%$ & $17.19 \%$ & $15.30 \%$ & $16.76 \%$ \\
35-44 years & $16.23 \%$ & $16.00 \%$ & $16.28 \%$ & $15.63 \%$ & $17.02 \%$ \\
45-54 years & $17.20 \%$ & $16.53 \%$ & $18.29 \%$ & $16.82 \%$ & $17.22 \%$ \\
55-64 years & $16.63 \%$ & $16.88 \%$ & $15.95 \%$ & $17.02 \%$ & $16.63 \%$ \\
65 years or more & $22.68 \%$ & $21.30 \%$ & $21.07 \%$ & $24.90 \%$ & $23.66 \%$ \\
\hline High school or less & $48.53 \%$ & $40.06 \%$ & $55.84 \%$ & $56.82 \%$ & $42.43 \%$ \\
Some college & $18.38 \%$ & $18.41 \%$ & $9.40 \%$ & $17.88 \%$ & $27.81 \%$ \\
Bachelor's degree & $23.14 \%$ & $27.53 \%$ & $27.63 \%$ & $14.24 \%$ & $22.55 \%$ \\
More than a & $9.95 \%$ & $14.00 \%$ & $7.13 \%$ & $11.06 \%$ & $7.21 \%$ \\
bachelor's degree & & & & & \\
\hline Income, Quintile 1 & $18.93 \%$ & $17.76 \%$ & $22.26 \%$ & $16.03 \%$ & $19.75 \%$ \\
Income, Quintile 2 & $19.54 \%$ & $21.47 \%$ & $15.32 \%$ & $25.05 \%$ & $16.15 \%$ \\
Income, Quintile 3 & $24.08 \%$ & $19.56 \%$ & $28.87 \%$ & $26.13 \%$ & $22.52 \%$ \\
Income, Quintile 4 & $20.06 \%$ & $22.89 \%$ & $14.26 \%$ & $17.54 \%$ & $25.02 \%$ \\
Income, Quintile 5 & $17.39 \%$ & $18.32 \%$ & $19.29 \%$ & $15.25 \%$ & $16.56 \%$ \\
\hline Instagram use & $39.80 \%$ & $42.24 \%$ & $38.39 \%$ & $36.36 \%$ & $41.91 \%$ \\
(yes=1/no=0) & & & & & \\
\hline Instagram use & $\mathrm{M}=1.95$ & $\mathrm{M}=2.06$ & $\mathrm{M}=1.93$ & $\mathrm{M}=1.81$ & $\mathrm{M}=1.98$ \\
(frequency, 1-4) & $\mathrm{SD}=1.23$ & $\mathrm{SD}=1.29$ & $\mathrm{SD}=1.24$ & $\mathrm{SD}=1.15$ & $\mathrm{SD}=1.21$ \\
\hline Accounts followed & $\mathrm{M}=2.49$ & $\mathrm{M}=2.75$ & $\mathrm{M}=2.57$ & $\mathrm{M}=2.22$ & $\mathrm{M}=2.36$ \\
(categories, 1-5) & $\mathrm{SD}=1.37$ & $\mathrm{SD}=1.42$ & $\mathrm{SD}=1.40$ & $\mathrm{SD}=1.24$ & $\mathrm{SD}=1.33$ \\
\hline Number of followers & $\mathrm{M}=2.40$ & $\mathrm{M}=2.69$ & $\mathrm{M}=2.43$ & $\mathrm{M}=2.15$ & $\mathrm{M}=2.24$ \\
(categories, 1-5) & $\mathrm{SD}=1.36$ & $\mathrm{SD}=1.42$ & $\mathrm{SD}=1.35$ & $\mathrm{SD}=1.25$ & $\mathrm{SD}=1.32$ \\
\hline Follow news & $16.21 \%$ & $18.11 \%$ & $14.19 \%$ & $16.94 \%$ & $15.35 \%$ \\
organization & & & & & \\
(yes=1/no=0) & & & & & \\
\hline$N$ Note The income quin $\%$ & & & \\
\hline & & & & & \\
\hline & & & & & \\
\hline
\end{tabular}

Note. The income quintiles are based on a specific country's income categories and distribution. They do not perfectly match the expectation of $20 \%$ in each quintile. 


\section{Results}

The Instagram use question was originally asked as a question about frequency of use, but when analyzing the data we simplified responses to understand the divide between users and non-users. Those who reported "never" using Instagram and those who did not reply to the question were coded as non-users. For our pooled sample of all countries (RQ1a), we find that $40 \%$ of respondents used Instagram $(n=6,291)$. Canada and the United States have similar patterns of usage, with approximately $42 \%$ of respondents using Instagram. As such, these countries do not differ in the adoption of Instagram (RQ1b). In the United Kingdom, 38\% of respondents use Instagram. In France, $36 \%$ use Instagram, which is the lowest of the four countries considered.

Large age differences are evident with respect to the adoption of Instagram (RQ1b). In all countries, about $73 \%$ of respondents aged 18 to 24 years use Instagram in contrast to $14 \%$ of seniors (Figure 1). In other words, Instagram usage is widespread among young adults. Canadians are distinctive in that older adults are more likely to use Instagram (21\%) than their counterparts in other countries (USA: 11\%, UK: 12\%, France: $13 \%)$.

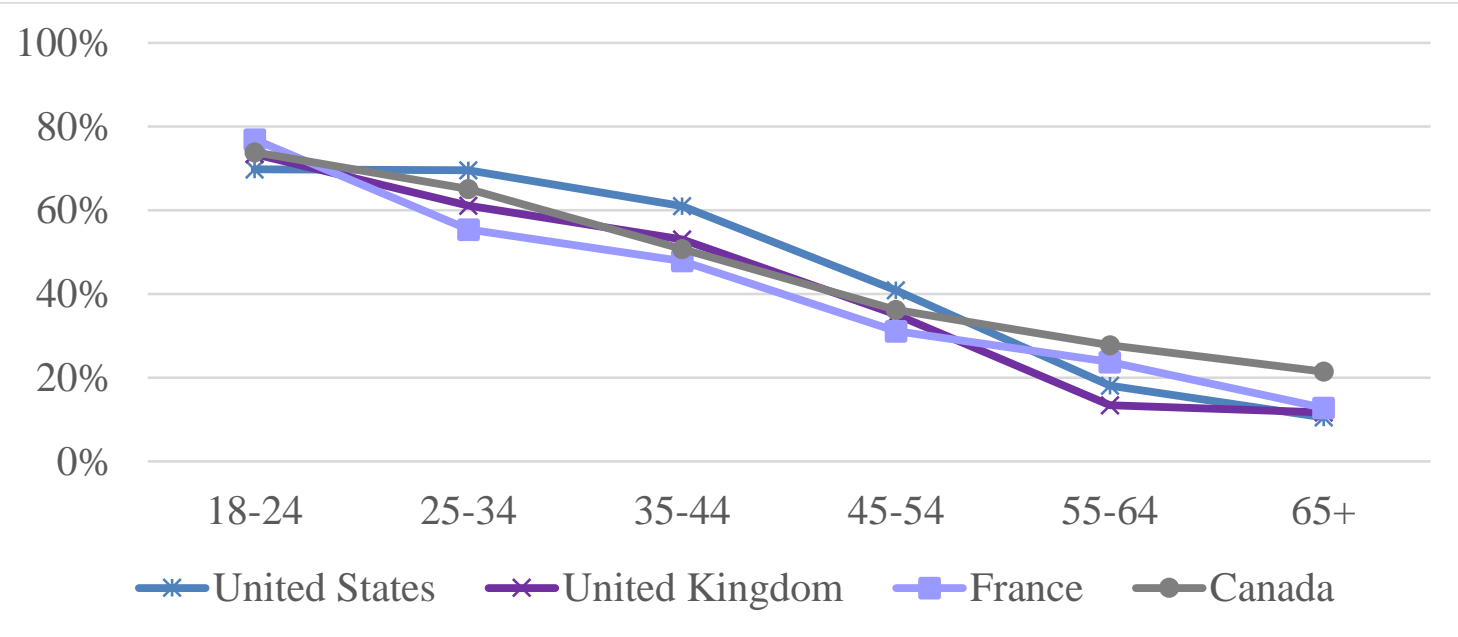

Figure 1. Age and Instagram use. 
Females are more likely to use Instagram compared to males (RQ1b); however, the magnitude of gender differences differs by country (Figure 2). No gender differences are apparent for the United States but large gender differences are evident for the United Kingdom. In a simple bivariate model, $26 \%$ of British males use Instagram compared to $51 \%$ of British females (Figure 2).

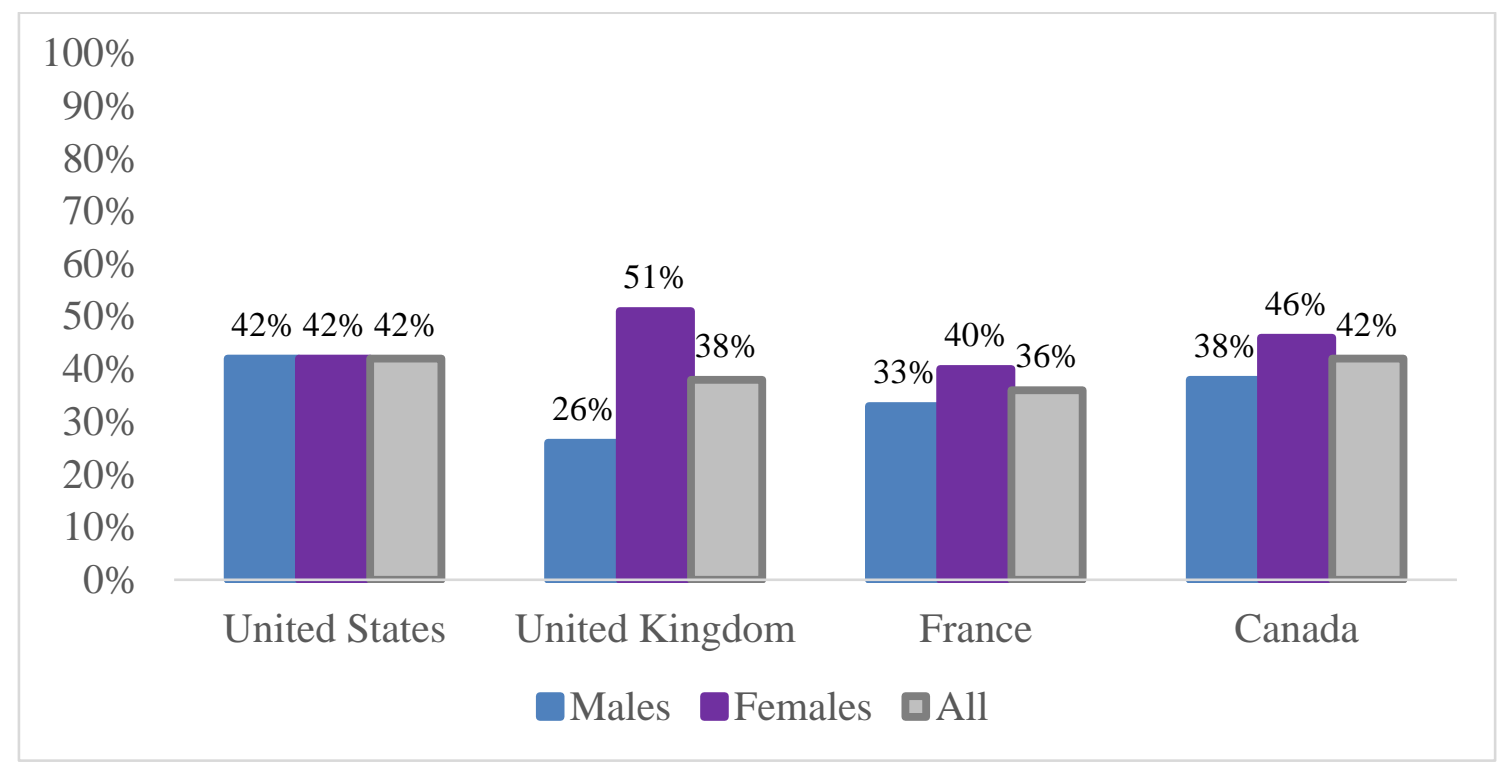

Figure 2. Gender and Instagram use.

In a multivariate model, those aged 18 to 24 years are 17 times more likely to use Instagram compared to those aged 65 years or more (Table 1). Gender differences in the use of Instagram are observed in the multivariate regression model (Table 1). However, the country-specific results suggest these differences are larger in the UK and not significant in the other three countries (RQ1b). In the multivariate model, there are no cross-national differences in Instagram use. Household income does not predict whether or not one uses Instagram (RQ1b). Having a bachelor's degree or more than a bachelor's degree increases the likelihood of using Instagram in the pooled sample (RQ1b). However, the country-specific results suggest these differences are only significant in the United States. 
Table 2. Logistic regression of Instagram use.

\begin{tabular}{|c|c|c|c|c|c|c|c|c|c|c|}
\hline & \multicolumn{2}{|l|}{ ALL } & \multicolumn{2}{|l|}{ USA } & \multicolumn{2}{|l|}{ UK } & \multirow{2}{*}{$\begin{array}{r}\text { France } \\
\operatorname{Exp}(B)\end{array}$} & \multicolumn{3}{|c|}{ Canada } \\
\hline & $\operatorname{Exp}(B)$ & $p$ & $\operatorname{Exp}(B)$ & $p$ & $\operatorname{Exp}(B)$ & $p$ & & $p$ & $\operatorname{Exp}(B)$ & $p$ \\
\hline Females & 1.233 & .001 & 1.072 & .566 & 1.567 & .001 & 1.233 & 0.096 & 1.147 & .248 \\
\hline 18-24 years & 17.394 & $<.001$ & 24.331 & $<.001$ & 18.832 & $<.001$ & 21.309 & $<.001$ & 11.372 & $<.001$ \\
\hline 25-34 years & 10.219 & $<.001$ & 19.121 & $<.001$ & 10.568 & $<.001$ & 9.423 & $<.001$ & 6.718 & $<.001$ \\
\hline $35-44$ years & 6.754 & $<.001$ & 12.165 & $<.001$ & 8.124 & $<.001$ & 6.997 & $<.001$ & 3.437 & $<.001$ \\
\hline 45-54 years & 3.375 & $<.001$ & 5.272 & $<.001$ & 4.084 & $<.001$ & 3.267 & $<.001$ & 2.042 & $<.001$ \\
\hline 55-64 years & 1.584 & $<.001$ & 1.763 & .017 & 1.229 & .447 & 2.400 & $<.001$ & 1.367 & .115 \\
\hline Some college & 1.032 & .706 & 1.097 & .590 & 0.933 & .753 & 1.124 & 0.488 & 1.001 & .996 \\
\hline Bachelor's degree & 1.343 & $<.001$ & 1.837 & $<.001$ & 1.262 & .130 & 1.362 & 0.108 & 1.047 & .770 \\
\hline $\begin{array}{l}\text { More than a bachelor's } \\
\text { degree }\end{array}$ & 1.426 & .001 & 1.895 & .001 & 1.168 & .551 & 1.486 & 0.063 & 1.182 & .484 \\
\hline Income, Quintile 2 & 1.027 & .783 & 1.170 & .408 & 1.186 & .415 & 0.662 & 0.036 & 1.298 & .187 \\
\hline Income, Quintile 3 & 0.932 & .450 & 1.019 & .923 & 0.928 & .679 & 0.800 & 0.258 & 0.890 & .524 \\
\hline Income, Quintile 4 & 1.123 & .236 & 1.176 & .408 & 1.116 & .614 & 1.132 & 0.567 & 1.046 & .800 \\
\hline Income, Quintile 5 & 1.180 & .113 & 1.558 & .033 & 1.088 & .683 & 0.724 & 0.184 & 1.403 & .091 \\
\hline United Kingdom & 0.876 & .119 & & & & & & & & \\
\hline France & 0.882 & .137 & & & & & & & & \\
\hline Canada & 1.126 & .154 & & & & & & & & \\
\hline Cox \& Snell R-square & .191 & & .249 & & .223 & & .179 & & .138 & \\
\hline$n$ & 5844 & & 1612 & & 1406 & & 1395 & & 1431 & \\
\hline
\end{tabular}

Note. The reference groups are males for gender, 65+ years for age, USA for country, high school for education, and the lowest quintile for income. 
Moving to frequency of use, rather than users versus non-users, we find that $9 \%$ use Instagram rarely, $13 \%$ use it sometimes, and $20 \%$ use it often (RQ1a). Strong age differences are evident with the two youngest age groups being the most frequent users (RQ1b). Among the youngest age group (18 to 24 years), half of respondents use Instagram "often" (Figure 3). Comparing the results across different countries, age is the strongest and most consistent determinant of Instagram use (Tables 2 and 3).

Canadians are similar to Americans in terms of frequency of use (Table 3); French and British respondents have slightly lower frequency of use, on average, compared to Americans. However, the country differences are quite small. Likewise, gender differences in frequency of use are also small (RQ1b). Again, it is the United Kingdom that is distinctive in higher frequency of use among females compared to males (Table 3). As noted with the prior analysis, having a bachelor's degree or more than a bachelor's degree increases the frequency of Instagram use, especially in the United States and France (Table 3).

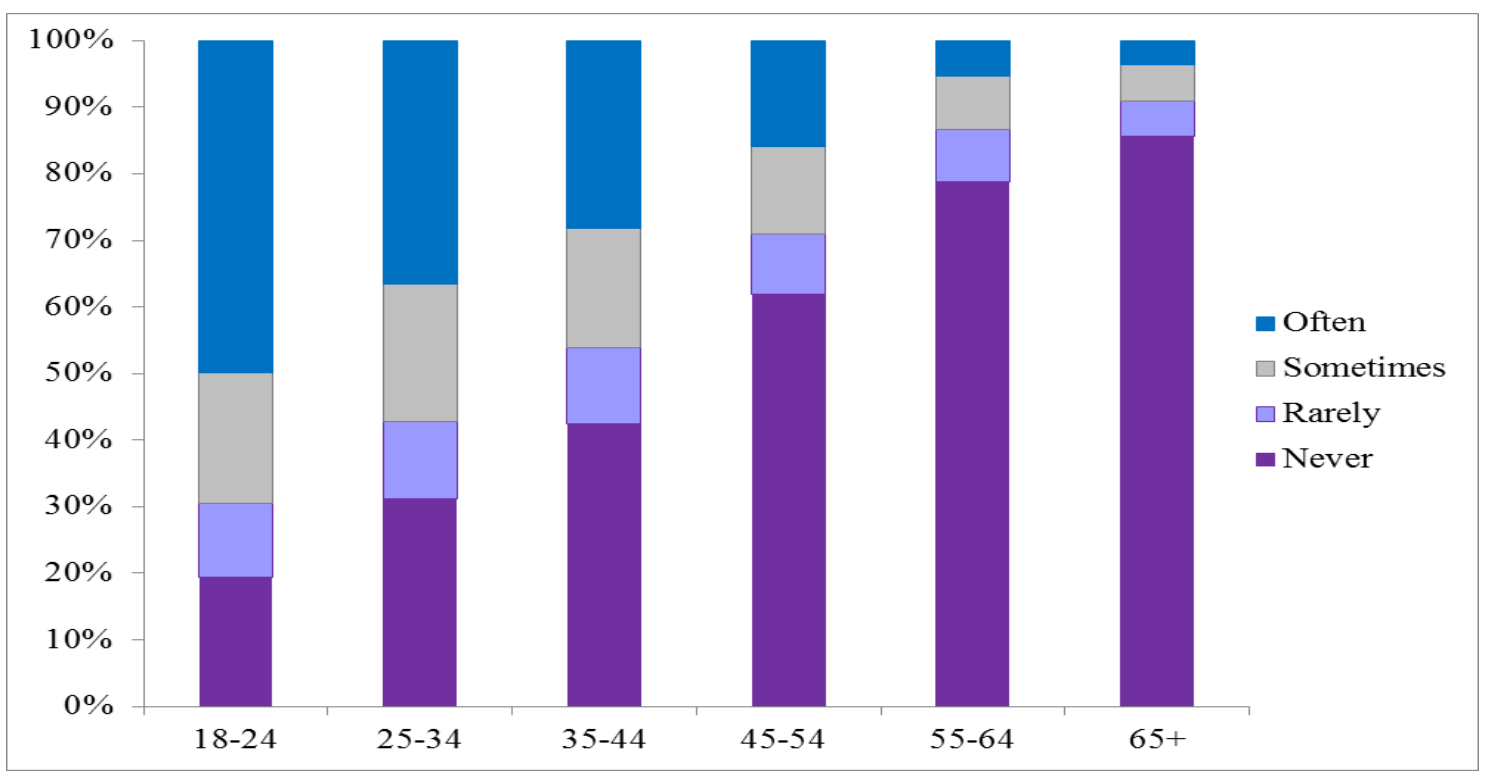

Figure 3. Age and frequency of Instagram use. 
Table 3. Ordinary Least squares regression of frequency of Instagram use.

\begin{tabular}{|c|c|c|c|c|c|c|c|c|c|c|}
\hline & \multicolumn{2}{|l|}{ ALL } & \multicolumn{2}{|l|}{ USA } & \multicolumn{2}{|l|}{ UK } & \multicolumn{2}{|l|}{ France } & \multicolumn{2}{|l|}{ Canada } \\
\hline & $\mathrm{B}$ & $p$ & $\mathrm{~B}$ & $p$ & $\mathrm{~B}$ & $p$ & $\mathrm{~B}$ & $p$ & $\mathrm{~B}$ & $\mathrm{p}$ \\
\hline Females & 0.059 & $<.001$ & 0.031 & .158 & 0.120 & $<.001$ & 0.063 & .011 & 0.049 & .051 \\
\hline $18-24$ years & 0.412 & $<.001$ & 0.437 & $<.001$ & 0.417 & $<.001$ & 0.420 & $<.001$ & 0.364 & $<.001$ \\
\hline 25-34 years & 0.393 & $<.001$ & 0.444 & $<.001$ & 0.390 & $<.001$ & 0.356 & $<.001$ & 0.375 & $<.001$ \\
\hline $35-44$ years & 0.304 & $<.001$ & 0.370 & $<.001$ & 0.304 & $<.001$ & 0.268 & $<.001$ & 0.249 & $<.001$ \\
\hline $45-54$ years & 0.170 & $<.001$ & 0.218 & $<.001$ & 0.178 & $<.001$ & 0.142 & $<.001$ & 0.131 & $<.001$ \\
\hline 55-64 years & 0.039 & .006 & 0.036 & .171 & 0.017 & .552 & 0.086 & .002 & 0.040 & .171 \\
\hline Some college & 0.001 & .906 & 0.004 & .855 & -0.012 & .618 & 0.021 & .409 & 0.005 & .860 \\
\hline Bachelor's degree & 0.053 & $<.001$ & 0.084 & .001 & 0.020 & .425 & 0.057 & .030 & 0.039 & .156 \\
\hline $\begin{array}{l}\text { More than a bachelor's } \\
\text { degree }\end{array}$ & 0.048 & $<.001$ & 0.078 & .002 & 0.020 & .433 & 0.069 & .009 & 0.015 & .577 \\
\hline Income, Quintile 2 & 0.004 & .790 & 0.010 & .719 & 0.029 & .292 & -0.057 & .092 & 0.045 & .137 \\
\hline Income, Quintile 3 & -0.007 & .652 & 0.008 & .792 & -0.017 & .567 & -0.025 & .470 & -0.005 & .886 \\
\hline Income, Quintile 4 & 0.015 & .347 & 0.028 & .358 & -0.001 & .983 & 0.034 & .307 & -0.004 & .901 \\
\hline Income, Quintile 5 & 0.036 & .021 & 0.080 & .008 & 0.029 & .339 & -0.052 & .127 & 0.065 & .039 \\
\hline United Kingdom & -0.036 & .010 & & & & & & & & \\
\hline France & -0.056 & $<.001$ & & & & & & & & \\
\hline Canada & -0.001 & .921 & & & & & & & & \\
\hline$R$-square & .258 & & .300 & & .294 & & .231 & & .222 & \\
\hline$n$ & 5542 & & 1527 & & 1328 & & 1345 & & 1339 & \\
\hline
\end{tabular}

Note. Standardized slopes (B) are reported for ordinary least squares regression. The reference groups are males for gender, $65+$ years for age, USA for country, high school for education, and the lowest quintile for income. 
Next, we examine social uses of Instagram. Users' network sizes are small (RQ2a). Specifically, 31\% report following 15 accounts or less, 26\% follow 16 to 100 accounts, 17\% follow 101 to 200 accounts, 13\% follow 201 to 400 accounts, and 13\% follow 400 accounts or more.

The age differences follow the patterns observed related to frequency of use. Younger people have much larger networks than older people (RQ2b). As illustrated in Figure 4, only $14 \%$ of young users follow fewer than 15 accounts, whereas more than $75 \%$ of seniors have these small user networks. Network sizes are smaller in Canada, France, and the United Kingdom than in the United States (RQ2b). French respondents have the smallest networks (Table 4). No significant gender differences are apparent in 
network size (Table 4). Those with higher education and income (socioeconomic status) follow more accounts than those with lower socioeconomic status (RQ2b).

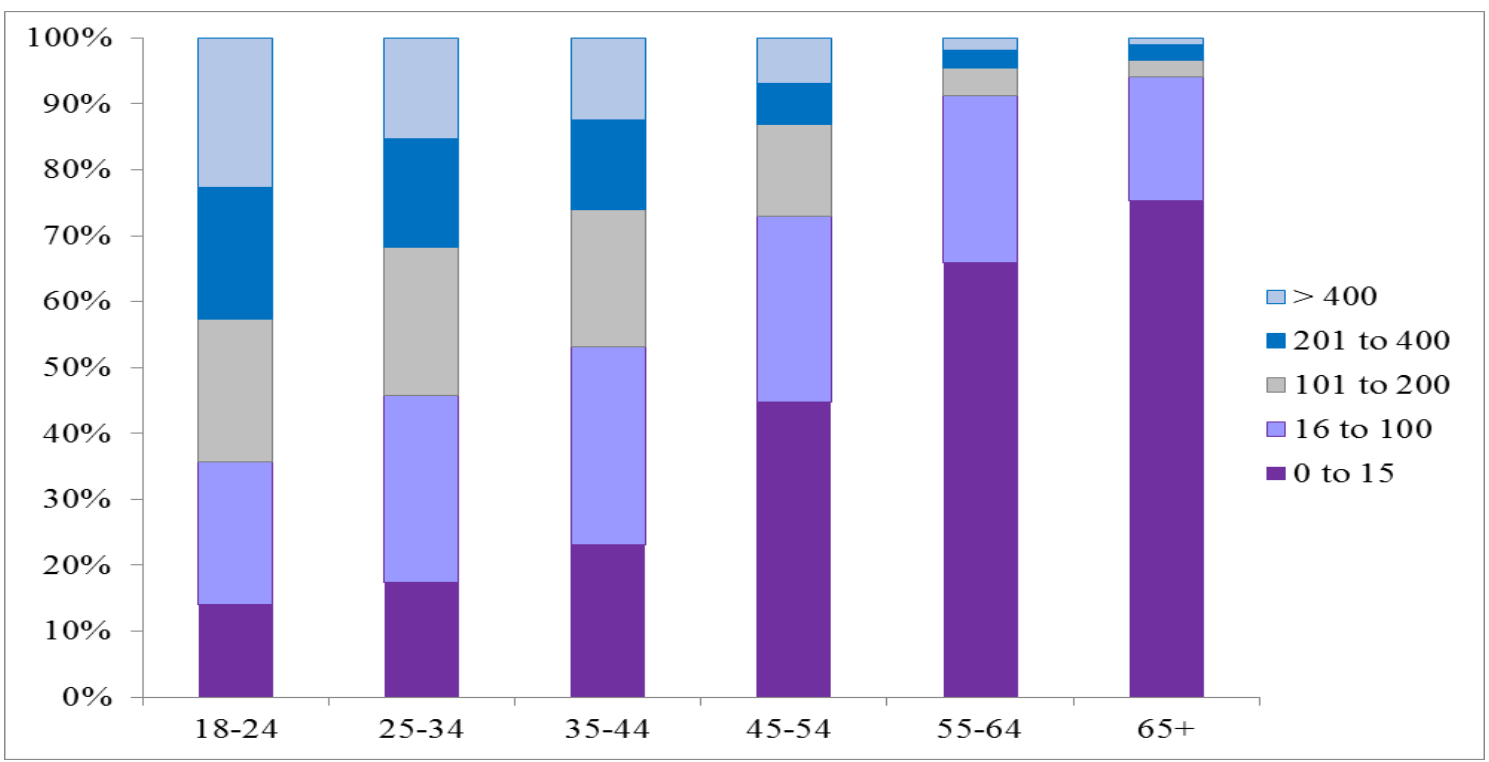

Figure 4. Age and number of accounts followed. 
Table 4. Ordinary least squares regression of the number of accounts followed.

\begin{tabular}{|c|c|c|c|c|c|c|c|c|c|c|}
\hline & ALL & & USA & & UK & & France & & Canada & \\
\hline & $\mathrm{B}$ & $p$ & $\mathrm{~B}$ & $p$ & B & $p$ & $\operatorname{Exp}(B)$ & $p$ & $\operatorname{Exp}(B)$ & $p$ \\
\hline Females & 0.032 & .088 & 0.044 & .229 & 0.046 & .244 & -0.023 & .574 & 0.032 & .388 \\
\hline $18-24$ years & 0.540 & $<.001$ & 0.496 & $<.001$ & 0.717 & $<.001$ & 0.545 & $<.001$ & 0.481 & $<.001$ \\
\hline 25-34 years & 0.479 & $<.001$ & 0.485 & $<.001$ & 0.525 & $<.001$ & 0.487 & $<.001$ & 0.456 & $<.001$ \\
\hline $35-44$ years & 0.388 & $<.001$ & 0.447 & $<.001$ & 0.395 & $<.001$ & 0.338 & $<.001$ & 0.419 & $<.001$ \\
\hline $45-54$ years & 0.191 & $<.001$ & 0.204 & .002 & 0.263 & $<.001$ & 0.206 & .001 & 0.137 & .007 \\
\hline 55-64 years & 0.050 & .051 & 0.033 & .529 & 0.054 & .275 & 0.072 & .222 & 0.042 & .372 \\
\hline Some college & 0.022 & .287 & 0.105 & .009 & -0.004 & .921 & -0.108 & .013 & 0.049 & .226 \\
\hline Bachelor's degree & 0.048 & .024 & 0.096 & .028 & 0.035 & .396 & -0.024 & .590 & 0.057 & .181 \\
\hline $\begin{array}{l}\text { More than a bachelor's } \\
\text { degree }\end{array}$ & 0.077 & $<.001$ & 0.096 & .031 & 0.072 & .088 & 0.061 & .190 & 0.088 & .024 \\
\hline Income, Quintile 2 & 0.019 & .404 & -0.020 & .671 & -0.008 & .857 & 0.064 & .215 & 0.044 & .335 \\
\hline Income, Quintile 3 & 0.066 & .006 & 0.108 & .024 & 0.055 & .253 & 0.068 & .206 & 0.018 & .703 \\
\hline Income, Quintile 4 & 0.047 & .055 & 0.019 & .724 & 0.006 & .894 & 0.085 & .112 & 0.068 & .162 \\
\hline Income, Quintile 5 & 0.057 & .023 & 0.051 & .326 & 0.002 & .966 & 0.058 & .291 & 0.092 & .055 \\
\hline United Kingdom & -0.066 & .003 & & & & & & & & \\
\hline France & -0.142 & $<.001$ & & & & & & & & \\
\hline Canada & -0.080 & $<.001$ & & & & & & & & \\
\hline r-square & .218 & & .174 & & .259 & & .192 & & .248 & \\
\hline$n$ & 2332 & & 677 & & 544 & & 507 & & 601 & \\
\hline
\end{tabular}

Note. Standardized slopes (B) are reported for ordinary least squares regression. The reference groups are males for gender, 65+ years for age, USA for country, high school for education, and the lowest quintile for income. 
While Instagram does not require reciprocal relations, the patterns of following are similar to patterns of followers. Specifically, 34\% report following 15 accounts or less, $26 \%$ follow 16 to 100 accounts, $17 \%$ follow 101 to 200 accounts, $11 \%$ follow 201 to 400 accounts, and $12 \%$ follow 400 accounts or more (RQ2a). The age differences follow the patterns observed related to frequency of use. Younger people have much larger networks than older people (RQ2b). As illustrated in Figure 5, only 15\% of young users have fewer than 15 followers, whereas about $81 \%$ of seniors have these small user networks.

As mentioned, network sizes are smaller in Canada, France, and the United Kingdom than in the United States (RQ2b). French respondents have the smallest networks (Table 5). There are small gender differences in the number of followers, largely attributed to the United Kingdom where females have larger networks than males (RQ2b). As observed related to following accounts, those with higher education and income (socioeconomic status) have more followers than those with lower socioeconomic status (RQ2b).

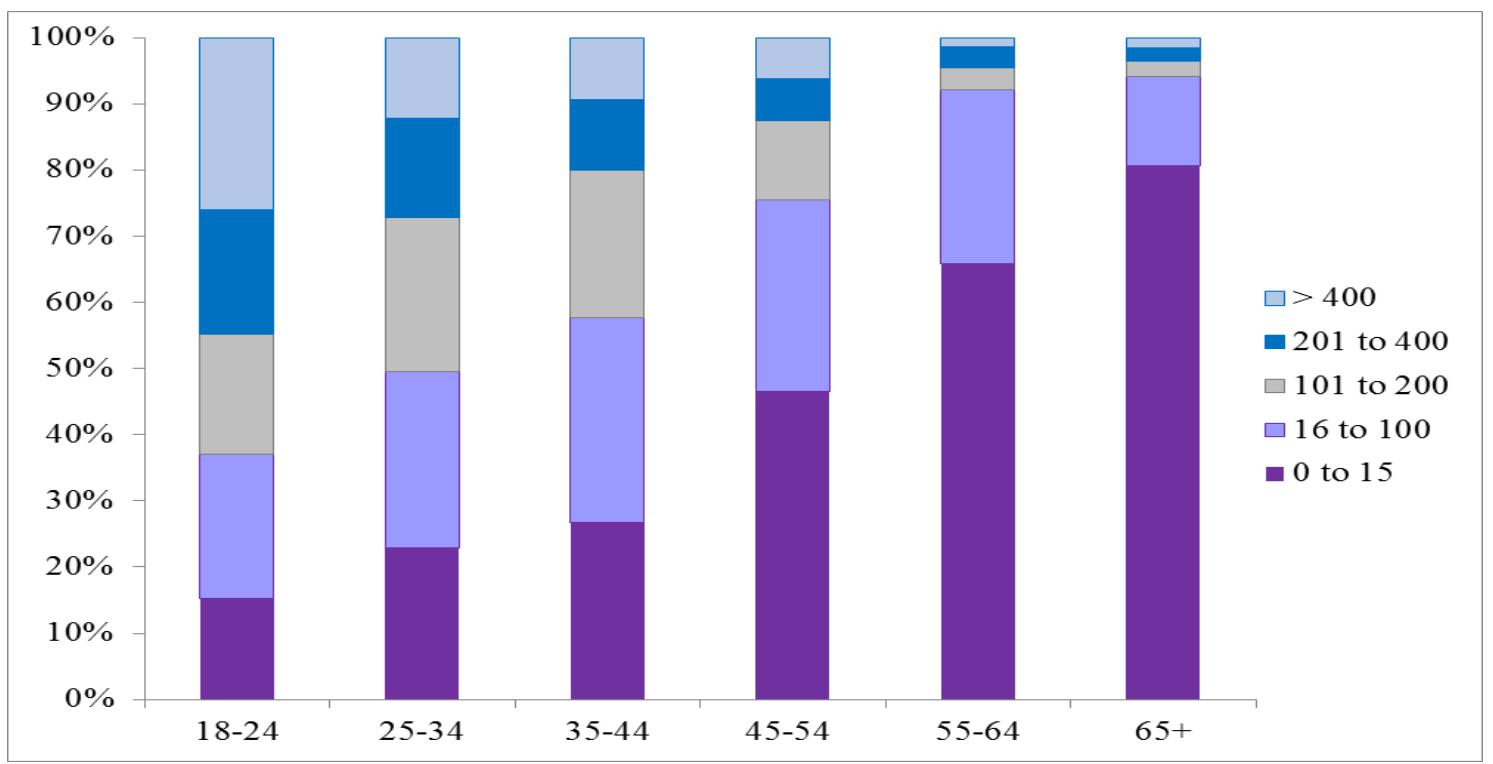

Figure 5. Age and numbers of followers. 
Table 5. Ordinary least square regression of number of followers.

\begin{tabular}{lllllllllll}
\hline & ALL & & USA & & UK & & France & Canada \\
\hline & $\mathrm{B}$ & $p$ & $\mathrm{~B}$ & $p$ & $\mathrm{~B}$ & $p$ & $\mathrm{~B}$ & $p$ & $\mathrm{~B}$ & $p$ \\
\hline Females & 0.041 & .027 & 0.058 & .113 & 0.078 & .048 & -0.025 & .547 & 0.023 & .523 \\
\hline 18-24 years & 0.569 & $<.001$ & 0.511 & $<.001$ & 0.738 & $<.001$ & 0.584 & $<.001$ & 0.527 & $<.001$ \\
25-34 years & 0.448 & $<.001$ & 0.455 & $<.001$ & 0.467 & $<.001$ & 0.484 & $<.001$ & 0.429 & $<.001$ \\
35-44 years & 0.357 & $<.001$ & 0.421 & $<.001$ & 0.366 & $<.001$ & 0.321 & $<.001$ & 0.360 & $<.001$ \\
45-54 years & 0.193 & $<.001$ & 0.208 & .002 & 0.257 & $<.001$ & 0.221 & $<.001$ & 0.124 & .015 \\
55-64 years & 0.055 & .031 & 0.030 & .563 & 0.067 & .173 & 0.091 & .125 & 0.049 & .296 \\
\hline Some college & 0.014 & .483 & 0.097 & .016 & -0.001 & .983 & -0.114 & .009 & 0.041 & .313 \\
Bachelor's degree & 0.039 & .065 & 0.081 & .064 & 0.045 & .275 & -0.033 & .456 & 0.040 & .342 \\
More than a bachelor's & 0.064 & .002 & 0.085 & .057 & 0.046 & .265 & -0.007 & .881 & 0.116 & .003 \\
degree & & & & & & & & & \\
\hline Income, Quintile 2 & 0.021 & .357 & 0.006 & .892 & 0.022 & .620 & 0.013 & .806 & 0.036 \\
Income, Quintile 3 & 0.087 & $<.001$ & 0.115 & .017 & 0.079 & .097 & 0.075 & .161 & 0.072 \\
Income, Quintile 4 & 0.061 & .012 & 0.050 & .344 & 0.021 & .643 & 0.062 & .246 & 0.093 & .055 \\
Income, Quintile 5 & 0.090 & $<.001$ & 0.115 & .028 & 0.045 & .351 & 0.071 & .196 & 0.112 & .018 \\
\hline United Kingdom & -0.098 & $<.001$ & & & & & & & \\
France & -0.150 & $<.001$ & & & & & & & & \\
Canada & -0.099 & $<.001$ & & & & & & &
\end{tabular}

Note. Standardized slopes (B) are reported for ordinary least squares regression. The reference groups are males for gender, 65+ years for age, USA for country, high school for education, and the lowest quintile for income. 
JQD: DM 2(2022)

In terms of Research Question 3 focusing on information uses, about $16 \%$ of users followed a news organization with males $(20 \%)$ being more likely to do so than females (14\%), but there are differences by country (Figure 6). In a multivariate model, gender differences are evident in following news organizations with females being less likely to follow compared to males (Table 6). Figure 7 displays the age differences in following news organizations. Compared to seniors, the three youngest age groups (ranging from 18 to 44 years) are three times more likely to follow a news organization on Instagram (Table 6). Education predicts following news organizations, particularly in the United States and Canada. Household income does not predict following news organizations in any of the four countries considered. There are no significant country differences in the likelihood of establishing ties to news organizations (Table 6, RQ3b).

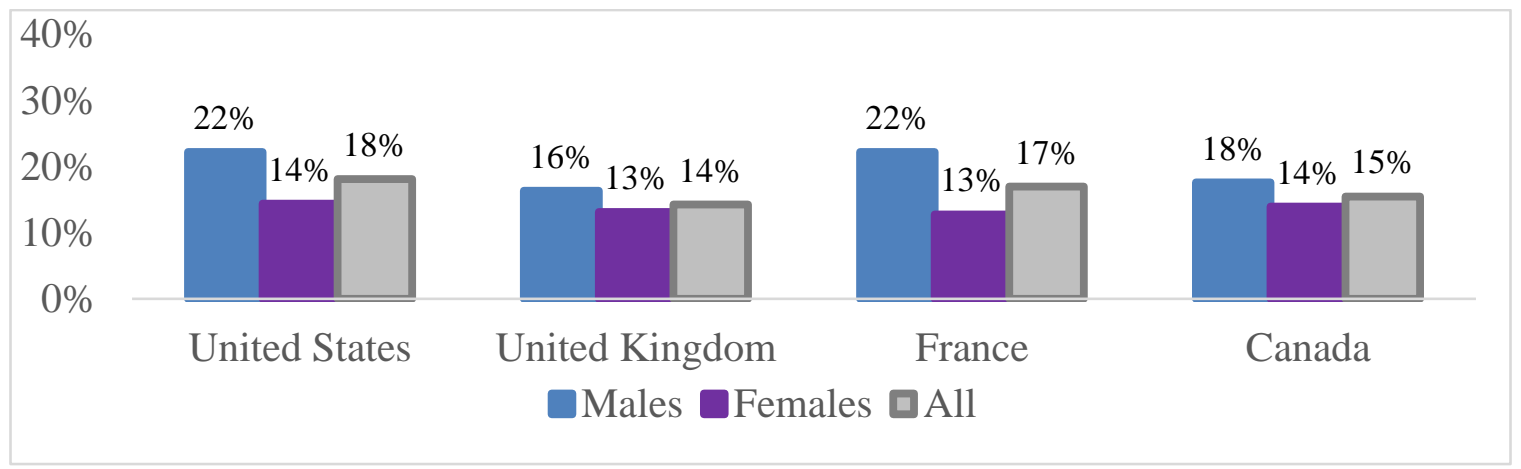

Figure 6. Gender and following news organizations.

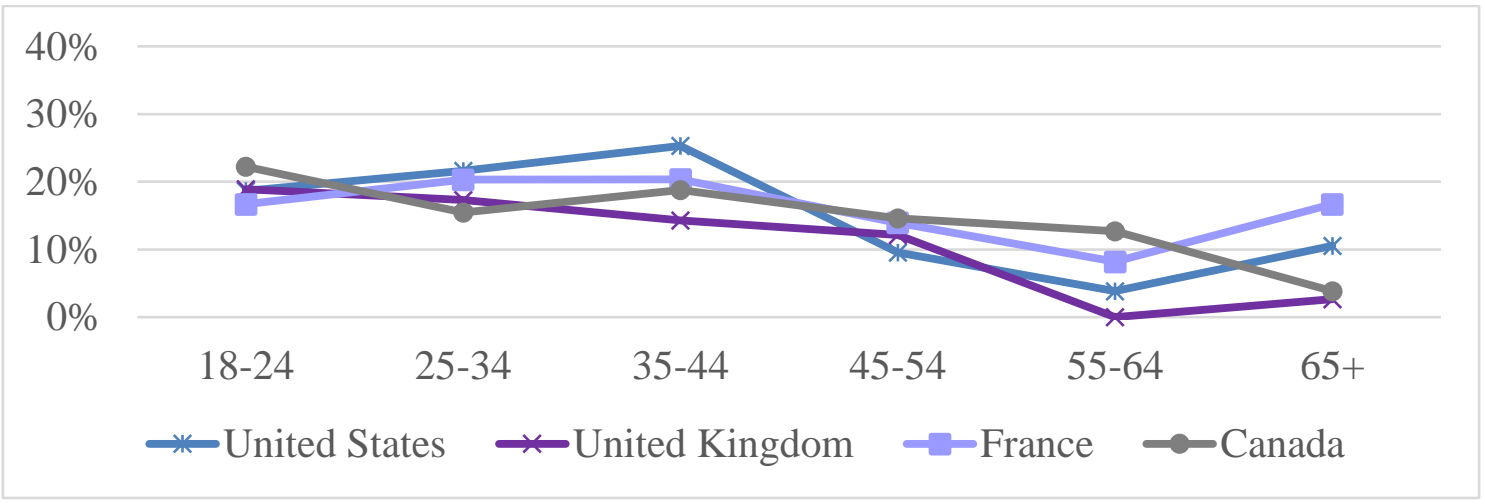

Figure 7. Age and following news organizations. 
Table 6. Logistic regression of following news organizations.

\begin{tabular}{|c|c|c|c|c|c|c|c|c|c|c|}
\hline & ALL & & USA & & UK & & France & & Canada & \\
\hline & $\operatorname{Exp}(B)$ & $\mathrm{p}$ & $\operatorname{Exp}(B)$ & $\mathrm{p}$ & $\operatorname{Exp}(B)$ & $\mathrm{p}$ & $\operatorname{Exp}(B)$ & $\mathrm{p}$ & $\operatorname{Exp}(B)$ & $\mathrm{p}$ \\
\hline Females & 0.587 & $<.001$ & 0.555 & .006 & 0.557 & .030 & 0.523 & .008 & 0.658 & .081 \\
\hline 18-24 years & 3.248 & $<.001$ & 2.209 & .179 & 12.399 & .017 & 1.146 & .790 & 8.334 & .001 \\
\hline 25-34 years & 2.918 & $<.001$ & 2.656 & .084 & 10.150 & .027 & 1.311 & .579 & 4.097 & .028 \\
\hline $35-44$ years & 2.735 & .001 & 3.080 & .048 & 6.300 & .082 & 1.093 & .856 & 4.954 & .013 \\
\hline $45-54$ years & 1.684 & .097 & 0.928 & .905 & 6.203 & .089 & 0.834 & .735 & 4.378 & .028 \\
\hline 55-64 years & 0.981 & .958 & 0.392 & .300 & 0.000 & .998 & 0.495 & .268 & 3.774 & .058 \\
\hline Some college & 1.304 & .112 & 1.269 & .461 & 1.137 & .762 & 1.549 & .171 & 1.289 & .440 \\
\hline Bachelor's degree & 1.725 & $<.001$ & 1.727 & .040 & 1.324 & .352 & 1.259 & .524 & 2.485 & .003 \\
\hline $\begin{array}{l}\text { More than a bachelor's } \\
\text { degree }\end{array}$ & 1.569 & .022 & 0.848 & .650 & 2.182 & .078 & 1.684 & .185 & 2.894 & .014 \\
\hline Income, Quintile 2 & 1.187 & .348 & 1.305 & .446 & 0.787 & .547 & 1.040 & .913 & 1.956 & .099 \\
\hline Income, Quintile 3 & 0.882 & .490 & 1.087 & .821 & 0.379 & .012 & 1.019 & .959 & 1.310 & .496 \\
\hline Income, Quintile 4 & 0.875 & .483 & 1.014 & .970 & 0.677 & .354 & 0.637 & .289 & 1.207 & .624 \\
\hline Income, Quintile 5 & 1.029 & .884 & 1.256 & .542 & 0.892 & .754 & 0.731 & .532 & 1.046 & .911 \\
\hline United Kingdom & 0.864 & .363 & & & & & & & & \\
\hline France & 1.068 & .678 & & & & & & & & \\
\hline Canada & 0.950 & .741 & & & & & & & & \\
\hline Cox \& Snell R-square & .035 & & .057 & & .063 & & .033 & & .054 & \\
\hline$n$ & 2333 & & 678 & & 545 & & 508 & & 602 & \\
\hline
\end{tabular}

Note. The reference groups are males for gender, 65+ years for age, USA for country, high school for education, and the lowest quintile 
JQD: DM 2(2022)

Instagram Use in Four Countries 25

\section{Discussion}

Relating these findings back to the $U \& G$ approach, we can draw some inferences on key motivations for Instagram use from the self-reported activities conducted using this platform. Current research suggests that social interaction and information are not primary motivations for Instagram use (Alhabash \& Ma, 2017; Shane-Simpson et al., 2018; Sheldon \& Bryant, 2016). We find some support for these findings. For the full sample of respondents across four countries, social networks are small and following news organizations is rare. Only $16 \%$ of users follow a news organization. There are no cross-national differences in information uses, but Americans have larger social networks suggesting greater social interaction motives.

The limited use of Instagram for news may be a key reason why recent studies on social media news and information (including mis-, dis- and malinformation) rarely focus on Instagram. However, our analysis does point to some user groups for whom Instagram constitutes a source of news. Findings on phenomena such as context collapse (Marwick \& boyd, 2011) and spiral of silence (Chen, 2018) indicate that network size and, relatedly, heterogeneity influence users' information-sharing behavior, with smaller, more homogeneous networks facilitating the spread of low-quality information (cf., Altay et al., 2020). This highlights the importance of taking network size into consideration when analyzing Instagram as a source of news. Our model fit for this variable is poor, suggesting that additional research should move beyond demographic factors and country differences to study informational uses.

A third of Instagram users have fewer than 15 followers and follow fewer than 15 other accounts. However, subgroups defined by age, gender, education, income, and country appear to have different motivations for use. In particular, young people have much larger social networks, implying stronger motivations for social interaction. We find some noteworthy differences in Instagram uses by age, gender, education, income, and country. While our models based on these variables are quite simple, the explained variance is quite high for patterns of use and size of social networks. Socioeconomic differences in Instagram adoption and types of uses are much smaller than the differences marked by age, gender, and country. Socioeconomic differences exist with respect to the size of social networks on Instagram, implying differences in social uses of this platform for those with higher education and income. Correa and Valenzuela (2021) 
examine use of four platforms, including Instagram, over time and find, using a sample of Chilean youth, that socioeconomic differences change over time.

Blank and Lutz (2017) did not find gender differences in Instagram usage, whereas we found strong gender differences in the UK context. Their data were collected in 2013 whereas ours were collected in 2019. They report that Instagram use was only 11\%, whereas our estimate is 38\% for the UK and 30\% according to the Digital News Report 2020 (Newman et al., 2020). While gender differences may not have been apparent in the early years, they have manifested in later stages. In contrast, we might say the opposite for studies in the USA. Gender differences were evident among student samples (Alhabash \& Ma, 2017; Kircaburun et al., 2020; Sheldon \& Bryant, 2016), but our American sample representative on age and gender suggests no gender differences. What we can see is that patterns of gender differences vary across countries and gender differences are apparent in types of use, particularly information uses, which moves scholarship forward. Using the U\&G approach, the lack of gender differences in social networks suggests females and males are equally likely to use this platform for social interaction. The gender differences in informational uses suggest males are more likely to use the platform for information.

Blank and Lutz (2017) find that digital skills predicted whether or not one used Instagram; they find a strong effect for digital skills and no significant differences for demographic variables using their UK survey. Hargittai (2020) also considered whether socioeconomic differences diminished when digital skills were considered in her models predicting use of Facebook, LinkedIn, and Twitter. For Facebook, Internet skills rather than socioeconomic differences predicted use; for LinkedIn, both socioeconomic differences and Internet skills predicted use; and for Twitter, income and Internet skills predicted use but education did not. Skills may mediate the relationship between motivations and behavior. This indicates a limitation of our approach, which we base on revealed preference theory (Chambers $\&$ Echenique, 2016). Moving beyond descriptive analyses, future research may explore the interaction of motivations, skills, and usage behavior.

In sum, our paper offers three unique contributions. First, we offer a comparison across four Western democracies. We show the frequency of Instagram use is similar in Canada and the 
USA. Second, we find that users' social networks on Instagram are quite small. Age and country predict different social network sizes. This platform is rarely used to establish direct ties to news organizations; the youngest age groups, males, and the well-educated are more likely to follow news organizations on Instagram. Third, as observed in other studies of social media platform adoption, we find strong age differences in use. These insights are important because most of the survey research on Instagram use has focused on college students at American universities (Alhabash \& Ma, 2017; Kircaburun et al., 2020; Shane-Simpson et al., 2018; Sheldon \& Bryant, 2016), which limits opportunities to measure the role of age. Focusing on the United States alone also offers a distorted view of Instagram use as Americans cultivate larger networks than respondents in other countries.

\section{Funding}

This project received funding from the Social Sciences and Humanities Research Council (SSHRC) Insight Grant (435-2019-04-94).

\section{References}

Alhabash, S., \& Ma, M. Y. (2017). A tale of four platforms: motivations and uses of Facebook, Twitter, Instagram, and Snapchat among college students? Social Media + Society, 3(1), 1-13. https://doi.org/10.1177/2056305117691544

Allen, J., Howland, B., Mobius, M., Rothschild, D., \& Watts, D. J. (2020). Evaluating the fake news problem at the scale of the information ecosystem. Science Advances, 6(14), eaay3539. https://doi.org/10.1126/sciadv.aay3539

Altay, S., Hacquin, A. S., \& Mercier, H. (2020). Why do so few people share fake news? It hurts their reputation. New Media \& Society, 1-22. https://doi.org/10.1177/1461444820969893

Blank, G., \& Lutz, C. (2017). Representativeness of social media in Great Britain: Investigating Facebook, LinkedIn, Twitter, Pinterest, Google plus, and Instagram. American Behavioral Scientist, 61(7), 741-756. https://doi.org/10.1177/0002764217717559

Bossetta, M. (2018). The digital architectures of social media: Comparing political campaigning 
on Facebook, Twitter, Instagram, and Snapchat in the 2016 U.S. election. Journalism \& Mass Communication Quarterly, 95(2), 471-496. https://doi.org/10.1177/1077699018763307

Chambers, C. P., \& Echenique, F. (2016). Revealed preference theory (Vol. 56). Cambridge University Press. https://doi.org/10.1017/CBO9781316104293

Chen, H. T. (2018). Spiral of silence on social media and the moderating role of disagreement and publicness in the network: Analyzing expressive and withdrawal behaviors. New Media \& Society, 20(10), 3917-3936. https://doi.org/10.1177/1461444818763384

Clement, J. (2019) Number of monthly active Instagram users, 2013-2018. Statista. Available at https://www.statista.com/statistics/253577/number-of-monthly-active-instagram-users/

Correa, T., Hinsley, A.W., \& Gil de Zúñiga, H. (2010). Who interacts on the Web?: The intersection of users' personality and social media use. Computers in Human Behavior, 26(2), 247-253. http://dx.doi.org/10.1016/j.chb.2009.09.003

Correa, T., \& Valenzuela, S. (2021). A trend study in the stratification of social media use among urban youth: Chile 2009-2019. Journal of Quantitative Description: Digital Media, 1, 143. http://dx.doi.org/10.51685/jqd.2021.009

Fletcher, R., Robertson, C. T., \& Nielsen, R. K. (2021). How many people live in politically partisan online news echo chambers in different countries? Journal of Quantitative Description: Digital Media, 1, 1-56. https://doi.org/10.51685/jqd.2021.020

Hands, D. W. (2013). Foundations of contemporary revealed preference theory. Erkenntnis, 78(5), 1081-1108. https://doi.org/10.1007/s10670-012-9395-2

Hargittai, E. (2020). Potential biases in big data: Omitted voices on social media. Social Science Computer Review, 38(1), 10-24. https://doi.org/10.1177/0894439318788322

Hargittai, E., \& Litt, E. (2012). Becoming a tweep: How prior online experiences influence Twitter use. Information, Communication and Society, 15(5), 680-702. https://doi.org/10.1080/1369118X.2012.666256

Hellemans, J., Willems, K., \& Brengman, M. (2020). Daily active users of social network sites: Facebook, Twitter, and Instagram-use compared to general social network site use. In F. 
JQD: DM 2(2022)

Instagram Use in Four Countries 29

J. Martínez-López \& S. D’Alessandro (Eds.), Advances in Digital Marketing and eCommerce (pp. 194-202). Springer International Publishing. http://dx.doi.org/10.1007/978-3-030-47595-6_24

Jenkins-Guarnieri, M. A., Wright, S. L., \& Hudiburgh, L. M. (2012). The relationships among attachment style, personality traits, interpersonal competency, and Facebook use. Journal of Applied Developmental Psychology, 33(6), 294-301. http://dx.doi.org/10.1016/j.appdev.2012.08.001

Kircaburun, K., Alhabash, S., Tosuntas, S. B., \& Griffiths, M. D. (2020). Uses and gratifications of problematic social media use among university students: A simultaneous examination of the Big Five of personality traits, social media platforms, and social media use motives. International Journal of Mental Health and Addiction, 18(3), 525-547. https://link.springer.com/article/10.1007/s11469-018-9940-6

Mantymaki, M., \& Islam, A. (2016). The Janus face of Facebook: Positive and negative sides of social networking site use. Computers in Human Behavior, 61, 14-26. http://dx.doi.org/10.1016/j.chb.2016.02.078

Marwick, A. E., \& Boyd, D. (2011). I tweet honestly, I tweet passionately: Twitter users, context collapse, and the imagined audience. New Media \& Society, 13(1), 114-133. https://doi.org/10.1177/1461444810365313

Newman, N., Fletcher, R., Schulz, A., Andi, S., \& Nielson, R. K. (2020). Digital News Report 2020. Reuters Institute, University of Oxford. http://www.digitalnewsreport.org

Ouwerkerk, J. W., \& Johnson, B. K. (2016). Motives for online friending and following: The dark side of social network site connections. Social Media + Society, 2(3), 1-13. https://doi.org/10.1177\%2F2056305116664219

Perrin, A., \& Andersen, M. (2019). Share of U.S. adults using social media, including Facebook, is mostly unchanged since 2018. Pew Research Center. https://www.pewresearch.org/fact-tank/2019/04/10/share-of-u-s-adults-using-socialmedia-including-facebook-is-mostly-unchanged-since-2018/

Petersen, M., Osmundsen, M., \& Tooby, J. (2020, August 29). The Evolutionary Psychology of Conflict and the Functions of Falsehood. https://doi.org/10.31234/osf.io/kaby9 
Quan-Haase, A., \& Young, A.L. (2010). Uses and gratifications of social media: A comparison of Facebook and Instant Messaging. Bulletin of Science, Technology \& Society, 30(5), 350-361. https://doi.org/10.1177\%2F0270467610380009

Russmann, U., \& Svensson, J. (2016). Studying organizations on Instagram. Information, 7(4), 1-12. https://doi.org/10.3390/info7040058

Ryan, T., \& Xenos, S. (2011). Who uses Facebook? An investigation into the relationship between the Big Five, shyness, narcissism, loneliness, and Facebook usage. Computers in Human Behavior, 27(5), 1658-1664. https://doi.org/10.1016/j.chb.2011.02.004

Shane-Simpson, C., Manago, A., Gaggi, N., \& Gillespie-Lynch, K. (2018). Why do college students prefer Facebook, Twitter, or Instagram? Site affordances, tensions between privacy and self-expression, and implications for social capital. Computers in Human Behavior, 86, 276-288. https://doi.org/10.1016/j.chb.2018.04.041

Shearer, E., \& Grieco, E., (2019). Americans are wary of the role social media sites play in delivering the news. https://www.journalism.org/2019/10/02/americans-are-wary-of-therole-social-media-sites-play-in-delivering-the-news/

Sheldon, P., \& Bryant, K. (2016). Instagram: Motives for its use and relationship to narcissism and contextual age. Computers in Human Behavior, 58, 89-97. https://doi.org/10.1016/j.chb.2015.12.059

Van Cauwenberge, A. \& Broersma, M. (2017). Understanding the mobilizing role of social media news use for political participation: How different social media technologies affect online political conversation. Paper presented at the annual conference of the International Communication Association, San Diego, May 25-29, 2017. 


\section{Appendix}

\begin{tabular}{|l|l|c|c|c|c|}
\hline Age & & USA & UK & France & Canada \\
\hline \multirow{3}{*}{$18-24$} & Official & $12 \%$ & $11 \%$ & $10 \%$ & $11 \%$ \\
\cline { 2 - 6 } & Survey & $11 \%$ & $11 \%$ & $10 \%$ & $9 \%$ \\
\hline \multirow{2}{*}{$25-34$} & Official & $18 \%$ & $17 \%$ & $15 \%$ & $16 \%$ \\
\cline { 2 - 6 } & Survey & $18 \%$ & $17 \%$ & $15 \%$ & $17 \%$ \\
\hline \multirow{3}{*}{$35-44$} & Official & $16 \%$ & $16 \%$ & $16 \%$ & $16 \%$ \\
\cline { 2 - 6 } & Survey & $16 \%$ & $16 \%$ & $16 \%$ & $17 \%$ \\
\hline \multirow{3}{*}{$45-54$} & Official & $17 \%$ & $18 \%$ & $17 \%$ & $18 \%$ \\
\cline { 2 - 6 } & Survey & $17 \%$ & $18 \%$ & $17 \%$ & $17 \%$ \\
\hline \multirow{2}{*}{$55+$} & Official & $37 \%$ & $37 \%$ & $42 \%$ & $39 \%$ \\
\cline { 2 - 6 } & Survey & $38 \%$ & $37 \%$ & $42 \%$ & $40 \%$ \\
\hline
\end{tabular}

\begin{tabular}{|l|l|cccc|}
\hline Sex & & USA & UK & France & Canada \\
\hline \multirow{3}{*}{ Male } & Official & $49 \%$ & $51 \%$ & $49 \%$ & $49 \%$ \\
\cline { 2 - 6 } & Survey & $48 \%$ & $51 \%$ & $49 \%$ & $46 \%$ \\
\hline \multirow{2}{*}{ Female } & Official & $51 \%$ & $49 \%$ & $51 \%$ & $51 \%$ \\
\cline { 2 - 6 } & Survey & $52 \%$ & $49 \%$ & $51 \%$ & $53 \%$ \\
\hline \multirow{2}{*}{ Non-binary } & Official & 0 & 0 & 0 & 0 \\
\cline { 2 - 6 } & Survey & $0.5 \%$ & $0.3 \%$ & $0.1 \%$ & $0.8 \%$ \\
\hline
\end{tabular}

$\underline{\mathrm{USA}}$

Age and sex (2017): Age in entire U.S. for 2017 American Community Survey $\underline{\mathrm{UK}}$

Sex and Age (2016):

https://www.ons.gov.uk/peoplepopulationandcommunity/populationandmigration/populationesti mates/bulletins/annualmidyearpopulationestimates/mid2016\#main-points

France

Age and sex (2018):

https://www.insee.fr/en/statistiques/2382609?sommaire=2382613 
Canada

Age groups and gender (2016):

https://www12.statcan.gc.ca/datasets/Index-

eng.cfm?Temporal $=2016 \&$ Theme $=115 \& V N A M E E=\& G A=-1 \& S=0$

\begin{tabular}{|c|c|c|c|c|c|}
\hline & & USA & UK & France & Canada \\
\hline \multirow[t]{2}{*}{ BASIC STUDIES } & Official & $42 \%$ & $56 \%$ & $56 \%$ & $45 \%$ \\
\hline & Survey & $40 \%$ & $56 \%$ & $57 \%$ & $42 \%$ \\
\hline \multirow{2}{*}{$\begin{array}{l}\text { ADVANCED } \\
\text { STUDIES }\end{array}$} & Official & $58 \%$ & $44 \%$ & $44 \%$ & $55 \%$ \\
\hline & Survey & $60 \%$ & $44 \%$ & $43 \%$ & $58 \%$ \\
\hline
\end{tabular}

$\underline{\text { USA }}$

Education (2015):

https://www.census.gov/data/tables/2015/demo/education-attainment/p20-578.html $\underline{\mathrm{UK}}$

Education (2011):

https://www.ons.gov.uk/employmentandlabourmarket/peopleinwork/employmentandemployeety pes/bulletins/keystatisticsandquickstatisticsforlocalauthoritiesintheunitedkingdom/2013-12-04

France

Education(June2017):https://publication.enseignementsup-

recherche.gouv.fr/eesr/10EN/EESR10EN_ES_20-

level_of_education_among_the_general_population_and_among_young_people.php

Canada

Education (2017):

https://www12.statcan.gc.ca/datasets/Index-

eng.cfm?Temporal $=2017 \&$ Theme $=123 \&$ VNAMEE $=\& \mathrm{GA}=-1 \& \mathrm{~S}=0$ 